\title{
Persistent reservations against the premedical and medical curriculum
}

\author{
Vinay Prasad
}

Published online: 15 March 2013

(C) The Author(s) 2013. This article is published with open access at Springerlink.com

Reflecting on medical education from the vantage of caring for patients, I am tempted to conclude that nearly every step is irrelevant for the next one. This is not a novel or profound observation. Emanuel [1] has argued that premedical curriculum (organic chemistry, calculus and physics) is not useful for clinical practice (nor most biomedical research). Previously, I have argued [2] that the first 2 years of medical school (biochemistry, molecular biology, neuroscience, physiology) are unnecessary for the second 2 years, and encourage a dangerous cognitive bias: subordinating evidence-based medicine to pathophysiological reasoning. This bias has been shown to play a key role in popularizing unproven medical practices [3], many of which are later overturned, a phenomenon called medical reversal [3]. Other critics have concluded rather bluntly that basic science education in the first 2 years of medical school is 'a waste of time' [4].

Similar criticism has been levelled against the Medical College Admissions Test, the United States Medical Licensing Exams, and field-specific medical board examinations. These tests have been criticized as: only weakly predicting medical school performance [5, 6], not being predictive of who does well in residency [7] (despite being used for that purpose), and not reflective of real world practice [8], respectively. Here, I wish to focus not on how we ended up in this situation-where every portion of professional training has been challenged (largely by following historical precedent) — nor on how training should be restructured (there have been countless suggestions) - but on the persistent arguments in favour of the status quo. Why do many believe we should not change our system of medical education, or worse, that we have already made the necessary changes?

\footnotetext{
V. Prasad $(\bowtie)$

Medical Oncology Branch, National Cancer Institute, National Institutes of Health, 10 Center Dr. 10/12N226, Bethesda, MD 20892, USA

email: vinayak.prasad@nih.gov
} 


\section{But, I learned critical thinking in organic chemistry}

The quintessential rebuttal to arguments that some portion of medical training is antiquated, esoteric and no longer relevant for practising clinicians is this one: but, organic chemistry teaches critical thinking. In fact, we can make this a generalizable statement: But, <insert your favourite class here $>$ was where I learned <critical thinking, logical reasoning, thinking on the fly, multitasking, visualizing problems, the ability to memorize large volumes of information, recall under pressure, etc. $>$. A version of this argument is ubiquitous. In response to Emanuel's critique of the premedical curriculum [1], one physician writes, 'I would not so hastily dismiss organic chemistry.... In a well-taught course, the specific facts... are secondary to the skills of pattern recognition, systematic analysis of complex problems, thinking in three dimensions...' Another group, defending the basic sciences, writes, 'Study in the sciences contributes to training in logical thinking and developing an inquisitive mindset that is integral to effective clinical reasoning [9].'

Although I can see its appeal, this argument is misguided. It is not fair to concede that the content of a course is irrelevant, but argue that, in the process, students learn some alternative, valuable skill. Because, if it is the case that hard work, critical thinking or <insert your favourite skill here $>$ is desirable among physicians, then we should teach that skill explicitly, or study the alternative ways to acquire the skill, and pick the path that best achieves that goal or does so in the least time. For instance, if the 'systemic analysis of complex problems' is a tool that good doctors need (and I tend to agree), is it organic chemistry, or a course in logic, or political science, or ancient Greek philosophy, or a novel course studying real-life medical problems that best inculcates this skill? And furthermore, how many years does it take? These are testable and important questions.

\section{But, without a mechanistic understanding, doctors will just be technicians}

Proponents of the basic sciences argue that the knowledge imparted in such courses is precisely what elevates physicians above the role of mere technicians, and to the status of professionals. Professionals understand the mechanistic rationale of why a therapy or diagnostic test makes sense, while technicians merely know under what circumstances they should be used. Technicians are perfectly able to function in the day-to-day management of even complicated issues, but when there are situations that do not neatly fit a predefined mould, only a professional can devise a plan, so the argument goes. Indeed, making decisions in the face of uncertainly may very well be the mark of a professional; however, a mechanistic understanding of science is just one way someone might navigate this.

In some cases, mechanistic reasoning may be completely mistaken. For instance, for a patient with heart failure caused by ischaemia, a mechanistic understanding of science would lead one to conclude that statin therapy should be beneficial. However, when directly examined this was not the case [10]. In our review of contradicted medical practices, we found that the most common reason practices were adopted and later contradicted was precisely because they were supported only by a mechanistic 
belief they would work [2]. Uncertainty is one of the core dilemmas faced by physicians, and we must have ways to reason in these situations. However, whether basic science is the best guiding salvo is far from certain. Elsewhere I have detailed other examples where mechanistic reasoning has mislead [2], and provided alternate ways to adjudicate uncertainty [3].

\section{But, we don't know who the next J. Michael Bishop will be}

Another common argument in favour of the status quo (that I frequently hear from the science faculty) is that we do not know who the next J. Michael Bishop, Roderick McKinnon, Harold Varmus, or <insert your favourite MD Nobel laureate here $>$ will be. Thus, we must continue to teach molecular biology, biochemistry, and related subjects so that, if a student in our ranks is destined to become a research giant, he or she will not have been deprived of the opportunity for early exposure to fundamental biomedical research.

It is easy to see why this argument lacks muster. Must every medical student be exposed to years of basic science coursework so that a select few may choose to focus on it? Surely, we can imagine less time-consuming screening tests. In a similar fashion, we also do not know who the next William Carlos Williams, Rivka Galchen, Khaled Hosseini, Michael Crichton or <insert your favourite doctor novelist here $>$ will be, but we do not make all physicians practice short story writing (although some might argue that it would foster empathy [11]).

The simple solution is to allow time for students to pursue diverse interests, without burdening those disinterested, while having a core medical curriculum address the common thread among MD graduates-providing care for patients. Most medical schools have the opportunity for electives in the final year; those who are interested can take basic science courses.

\section{But, basic science is the foundation for medical education}

Lastly, we come to the most common defence of basic science in premedical and medical education: that it is the foundation, period. Basic science remains as important as it did in Flexner's time. One group reaches this conclusion after internal discussion, 'Our findings revealed a consensus with Flexner's view in 1910regarding both the basic sciences (anatomy, biochemistry, neuroscience, physiology, microbiology, immunology, pathology, and pharmacology) that a preclinical medical education should include and the fact that these sciences remain vital foundations of medical practice [9].' Another writer concurs, 'Knowledge of the applications of biochemistry, molecular biology, and genetics in the practice of medicine has been and continues to be a vital part of medical students' and continuing education [12].

The assertion that basic science is the foundation of clinical medicine is common, and frequently made by those who teach the courses in question. However, claiming that some coursework is the foundation for future practice does not make sense, if, in 
that future practice, the prior coursework is never used [13]. Simply because it was mandated does not make biochemistry a foundation.

\section{But, we've already made changes}

The final objection is that we have already made dramatic changes to medical education. A 1983 report [14] called for a movement away from detail-oriented medical education, a 1992 report asked that basic science be made relevant by being incorporated throughout all 4 years [15]. Many medical schools have made changes to the curriculum in response to these calls; however, such reforms often reorganize basic science curricula (into organ systems, for instance), and fail to question their fundamental value. A high profile article on medical education reform suggests, rather meekly, that other competencies be added to the 'traditional biomedical content' [16]. 'For this reason, others have called such reforms, 'cosmetic' in nature [4].

The case against organic chemistry, physics, calculus (premed), biochemistry, molecular biology, (prolonged, i.e. 20 weeks of) anatomy, neuroscience, embryology, and even histology has been made repeatedly in the medical education literature. Despite the many arguments from practising physicians that this subject matter is not used daily in clinical medicine, and, despite the further criticism that such bottom up learning sanctions cognitive biases [2], there has been little real change in medical education, as these courses continue to be mandated. Several groups $[1,4,15]$ note that other competencies-statistics, bioethics, communication, and health policy_are more deserving of a place in the medical curriculum than most basic science. But this argument is overly generous, and likely intended as a compromise. All classes should be evaluated by the same standard of relevance, and reasons for omitting basic science go beyond considerations of what might fill its place. Here, I have tried to articulate the common objections in favour of the status quo. None carry strong appeal. Regardless of what we add to medical education, we must cut subjects that are not used by the vast majority of graduating physicians.

Open Access This article is distributed under the terms of the Creative Commons Attribution License which permits any use, distribution, and reproduction in any medium, provided the original author(s) and the source are credited.

\section{References}

1. Emanuel EJ. Changing premed requirements and the medical curriculum. JAMA. 2006;296:1128.

2. Prasad V. Beyond storytelling in medicine: an encounter based curriculum. Acad Med. 2010;85: 794-8.

3. Prasad V, Gall V, Cifu A. The frequency of medical reversal. Arch Intern Med. 2011;171(18):1675-6.

4. Rajan TV. Making medical education relevant. Chron High Educ. 2006;52:20.

5. Donnon T, Paolucci EO, Violato C. The predictive validity of the MCAT for medical school performance and medical board licensing examinations: a meta-analysis of the published research. Acad Med. 2007;82(1):100-6. 
6. Callahan CA, Hojat M, Veloski J, Erdmann JB, Gonnella JS. The predictive validity of three versions of the MCAT in relation to performance in medical school, residency, and licensing examinations: a longitudinal study of 36 classes at Jefferson medical college. Acad Med. 2010;85:980-7.

7. McGaghie WC, Cohen ER, Wayne DB. Are United States medical licensing exam step 1 and 2 scores valid measures for postgraduate medical residency selection decisions? Acad Med. 2011;86:48-52.

8. Ofri, Danielle. Being a med student, take two. New York Times. http://well.blogs.nytimes.com/2011/ 11/03/being-a-med-student-take-two/. Accessed 17 Dec 2011.

9. Finnerty E, Chauvin S, Bonaminio G, et al. Flexner revisited: the role and value of the basic sciences in medical education. Acad Med. 2010;85:349-55.

10. Kjekshus J, Apatrei E, Barrios V, et al. Rosuvastatin in older patients with systolic heart failure. N Engl J Med. 2007;357:2248-61.

11. Charon R. The narrative road to empathy. In: Spiro HM, McCrea Curnen MG, Peschel E, St. James D, editors. Empathy and the practice of medicine: beyond Pills and the scalpel. New Haven: Yale University Press; 1993.

12. Smith HC. A course director's perspectives on problem-based learning curricula in biochemistry. Acad Med. 2002;77:1189-98.

13. Patel V, Groen SJ, Scott HM. Biomedical knowledge in explanations of clinical problems by medical students. Med Educ. 1988;22:398-406.

14. Friedman CP, Purcell E, De Bliek R, editors. The new biology and medical education: merging the biological, information, and cognitive sciences. New York: Josiah Macy, Jr. Foundation; 1983.

15. Marston RQ, Jones RM. Commission on medical education: the sciences of medical practice. medical education in transition. Princeton: The Robert Wood Johnson Foundation; 1992.

16. Cooke M, Irby DM, Sullivan W, Ludmerer KM. American medical education 100 years after the Flexner report. N Engl J Med. 2006;355:1339-44.

\section{Author Biography}

Vinay Prasad MD, is chief fellow in Medical Oncology at the National Cancer Institute. Dr. Prasad coined the term 'medical reversal' and has published on the subject in the Journal of the American Medical Association and Archives of Internal Medicine, among others. His interest is the rational adoption of medical practice. 